\title{
Applying the Möbius Strip Model to Corporate Social Responsibility: Survey-Based Findings from Italian Social Enterprises
}

\author{
Francisco Lopez Arceiz \\ Department of Accounting and Finance (FECEM) \\ University of Zaragoza, Italy \\ Nazaria Solferino \\ Economics Department \\ University of Rome "Tor Vergata", Italy \\ Viviana Solferino \\ Mathematics and Computer Science Department \\ University of Calabria, Italy \\ Ermanno C. Tortia \\ Department of Economics and Management \\ University of Trento, Italy \\ Received 15 March 2017 \\ Accepted 6 June 2017 \\ Published 6 July 2017
}

\begin{abstract}
In this work, we apply the electro-magnetism geometrical model of the Möbius Strip in the context of Corporate Social Responsibility (CSR) in order to test the relationship between CSR and organizational performance. We exploit a unique dataset that includes 4135 workers in a matched sample of 320 Italian social enterprises. Results show that CSR is the strongest determinant of firm performance, although there is an indirect effect of cooperation and worker alienation in terms of higher job satisfaction.
\end{abstract}

Keywords: Corporate social responsibility; econophysics; firm behavior; firm performance; structural equations modeling.

JEL Classification: C3, D21, L13, Z1

This is an Open Access article published by World Scientific Publishing Company. It is distributed under the terms of the Creative Commons Attribution 4.0 (CC-BY) License. Further distribution of this work is permitted, provided the original work is properly cited. 


\section{Introduction}

The analysis of the interdependence of social and economic relationships and the social role of entrepreneurial organizations requires dedicated theories and suitable tools, more so in the contemporary context of heightened competition in the globalized economy. Interdependence implies multiple positive and negative feedback loops making system interdependent and interacting dissipatively with their environment. ${ }^{47}$

In Economics, this interdependence among systems and among agents is just the core of the models of Corporate Social Responsibility (CSR), which consider the global integration between firms and their stakeholders, including workers, customers and the whole socio-economic and natural environment. ${ }^{5}$ Sacconi ${ }^{42}$ discusses CSR for the generality of businesses and defines it within the social contractarian tradition as enlarged governance that extends the fulfilment of the firm's fiduciary duties towards all of its stakeholder groups. ${ }^{2,9}$ CSR is a norm that emerges spontaneously as a contractarian solution in an equilibrium selection process, leading to the creation of a corporate governance institution. It also allows deducing a multistakeholder objective function. CSR has been seen as a norm that can favor, not halt, organizational and production performance through the inclusion of different stakeholder groups in corporate governance. ${ }^{36}$

CSR implies the move from the maximization of shareholder value to the satisfaction of a more complex objective function in which varied stakeholder interests are taken into account. In turn, this creates benefits also for businesses. For instance, Becchetti et al. ${ }^{5}$ show that, since more and more profit maximizing firms are adopting CSR practices, there must be pecuniary benefits to such practices. The authors also document that CSR has the potential to generate several value increasing effects by attracting better employees, and enhancing their intrinsic motivation and loyalty, by reducing turnover rates, by improving production efficiency and by reducing operating costs.

Furthermore, CSR boosts sale revenues and attracts more ethical consumers, so that the firm can benefit from increases in its demand share. Other authors show positive linkages between socially responsible behaviors and individual or organizational outcomes, such as worker satisfaction ${ }^{44}$ and firm location decisions. ${ }^{26}$ All the above mentioned advantages can be seen as a sort of ethical capital accumulated trough CSR practices, which also requires the payment of additional costs. Becchetti et $a l .^{5}$ underline, by using a dynamic model, the conditions required to obtain that such benefits overrun the costs. These advantages can also be understood as the result of the synergy which relates each subsystem's and each agent's performance. Thanks to this synergy, net benefits flow across stakeholder groups by virtue of their connections with the firm and of intra-organizational cooperation, which generates net transactional benefits across the business system.

Several works deal with the benefits for stakeholders and in particular for workers that arise by investing in CSR. Within this field of enquiry, many analyses use the 
standard taxonomy of CSR criteria provided by Kinder, Lydenberg and Domini Research and Analytics, Inc. (KLD). They include the following eight wide-ranging categories into the Domini 400 index: (i) community; (ii) corporate governance; (iii) diversity; (iv) employee relations; (v) environment; (vi) human rights; (vii) product quality; and (viii) controversial business issues. Every category has its strengths and weaknesses identified and analyzed within the index, as well as the suggestion of corporate activities compliant with each specific category. For instance, by using the KLD index, Becchetti et $a l .{ }^{6}$ showed that CSR firms, which take into account workers' well-being, are less exposed to business risks and profit volatility. Other authors analyzed the effects of increased productivity of individual workers. ${ }^{39}$ The authors showed how specific investments in CSR can be seen as the optimal incentive system that prompts employees to allocate greater effort in cooperative tasks because they derive utility from cooperation. In the meta-analysis devised by Harter et al. ${ }^{27}$ positive workplace perceptions and feelings are associated with higher business-unit customer loyalty, higher profitability, higher productivity and lower turnover. In Gond et al. ${ }^{25}$ it is explained how employees' perceptions of CSR trigger attitudes and behaviors in the workplace, which affect organizational, social and environmental performance. Myers and Sadaghiani ${ }^{35}$ added an analysis specifically directed to the benefits of cooperation between coworkers and discuss the effects of firm's values and workplace interaction on coworkers. Finally, using data collected from employees in three private airline companies in Iran, Rast and Jourani ${ }^{38}$ showed that an important factor impacting on job satisfaction and productivity is the relationship with co-workers. In connection with the literature on social capital, Degli Antoni ${ }^{19}$ evidenced that individual motivations akin to socially responsible behavior (the desire to be useful to others and ideal motivations) enable people to extend their social networks by creating relations characterized by familiarity. Degli Antoni and Portale $^{20}$ analyzed the effects of CSR pointing out how the adoption of CSR good practices fosters the creation of workers' social capital understood as cooperative networking, generalized trust, and relational skills. Relatedly, Sabatini et al. ${ }^{14}$ worked on the cognitive dimension of social capital (within the literature developed by), ${ }^{23,29,37,40}$ and found out that people employed in organizations characterized by inclusive governance and community-oriented objectives, such as cooperative enterprises, are more prone to strengthen overtime the degree of their generalized social trust.

Following these premises, our CSR standpoint posits that firms and stakeholders can be depicted not as two distinct and unconnected systems, but instead as crossed-systems where transfers occur in such a way that businesses co-evolve with the stakeholders' interests, which become part of the business. In this crossedsystem, the output of each part is transferred across the other parts to become the others' input, so that these subsystems are strongly overloaded and linked inextricably together.

According to our viewpoint, we need models taking into account this complexity and nonlinearity in the connections. We submit that the best metaphor, suggested by 
and analyzed in the physical sciences, to approximate and represent this new conceptualization of CSR and more generally of fundamental linkages among stakeholders in economic systems and between agents, is the Möbius strip.

This is a topological enigma independently documented in 1858 by two mathematicians A. F. Möbius and J.B. Listing. It is a bend of paper that is given a 180 degree twist prior to having its two ends connected. The first use of the Möbius strip as a metaphor in business relationships is found, to the best of our knowledge, in Litz ${ }^{31}$ who discussed an alternative approach to business family and family business relationships.

In our contribution, we aim at extending this approach to CSR analysis by extensively relying on recent discoveries in electromagnetism. We assimilate firms and their stakeholders' contributions to the action of electrons traveling a Möbius strip which, unlike a regular bend, return to a mirror reality in each count. In particular, we strictly follow the model of Yakubo et al. ${ }^{49}$ who show that the electrons traveling on a Möbius strip produce energy of higher intensity or, equivalently, that there is lower energy dissipation thanks to decreased resistance by virtue of the twist in the bend. We analyze how the contributions of economic agents in a CSR context, thanks to the effects on ethical capital, produce higher benefits and lower dissipation in terms of lower costs thanks to augmented cooperation.

The paper is divided into four sections (including introduction and conclusions). In the second section, we describe how the geometrical model for the electrons traveling on a Möbius strip is built. In the third section, we investigate how to apply this model to the behavior of firms and economic agents in a CSR context. We define a new cost function that shows the convenience to invest in socially responsible activities thanks to three positive crossed effects on efficiency: (i) cooperation within the same group of stakeholders; (ii) cooperation among similar stakeholders in different sectors of the firm; (iii) stakeholders' loyalty towards the company. We provide an example of a firm's decisional problem in which the firm decides whether to invest in social responsibility activities. Our analytical results show that this is always the optimal choice depending on the number of stakeholder groups, on stakeholders' sensitivity to these investments and on the decay rate to alienation. We empirically test our findings on survey data in the third section. The survey deals with labor relations and CSR and involves 4135 workers employed by 320 matched Italian cooperatives working in the social service sector (the so called "Cooperativa Sociale" as defined by law n. 381/1991). The survey (ICSI 2007) was conducted nationally by a pool of 5 university departments. Social cooperatives are the most relevant and fastest growing ${ }^{\mathrm{a}}$ instance of social enterprise in Italy since they alone

\footnotetext{
a Social cooperatives started from scratch in 1991, when law 381 on the "Cooperativi Sociali" was passed by the Italian Parliament. In 2013, about 11,000 social cooperatives employing 390,000 workers were recorded by official statistics. ${ }^{12,22}$
} 
accomplish about $30 \%$ of total production and employment in the social service sector. ${ }^{22 \mathrm{~b}}$ They are mutual benefit entrepreneurial organizations characterized by a (partial) nonprofit distribution constraint, socialization of the firm assets, multistakeholder governance, and by a social aim spelled out in statutory bylaws. Hence, they all produce private, but meritorious goods and services.

In the empirical part, we test our cost-benefit model by analyzing the impact of CSR and organizational processes, which represent a proxy for increased propensity to cooperation, on net benefits in terms of organizational performance. Our empirical results show that CSR is, in all specifications of the model, the strongest determinant of firm performance in terms of improvement in service quality and achieved professional and personal growth. These results hold true after controlling for several socio-economic features of the workforce, and for firm size and macro-regional location within Italy. Positive and strong direct effects of CSR on performance are added to indirect effects mediated by organizational patterns informed by cooperation and reduced worker alienation in terms of higher on-the-job satisfaction.

\section{Theoretical Model}

\subsection{The model of the "Möbius strip-like-CSR economy"}

In this paper, we want to empirically investigate the theoretical results by Solferino and Solferino, ${ }^{45}$ who draw extensively from the analogies with the behavior of fermions (a typology of electrons) moving on a Möbius strip to show what kind of interactions among stakeholders are at work and affect improvements in a company's performance. In this section, we shortly describe the main features of the model which relies on the consideration that the twist in a Möbius strip generates two important effects on the electrons' trajectories and on the energy produced. First, unlike a cylinder, in a Möbius strip an electron moves in the longitudinal direction along the ring, encircling the system twice before returning to its initial position. This movement creates flux periodicities generating more persistent electric current. Second, the electrons move also in the transverse direction, so that they can tunnel to their neighbors in more directions. Finally, thanks to the twist the electrons in the last wire tunnel in the same wire on the corresponding replicated new element. Similarly, in a CSR company, the SR investments just like the twist should make stakeholders' relationships closer and more persistent, so that one stakeholders' interest (the fermions) becomes the others' interest too. ${ }^{\mathrm{c}}$ As foreshadowed also by

\footnotetext{
$\mathrm{b}$ The remaining $70 \%$ of the Italian social service sector is occupied by public sector organizations (about $25 \%$ ), by traditional nonprofit organizations (associations and foundations, which are not considered enterprises by the Italian civil code, about $40 \%$ ), and by profit-making, investor owned companies (about $5 \%$ ).

${ }^{\mathrm{c}}$ Fermions are similar to the contributions of stakeholders who clearly are proportional to their interests. The $n$ stakeholders and the $m$ sectors are the vertical and horizontal stripes that make up the tape of the Möbius strip. They are located on both sides. The twist pushes all of them closer to each other, closing up the relationship of all the $m$ with all the $n$. In our case, the $n$ workers with the interests and $m$ different sectors of their cooperative.
} 


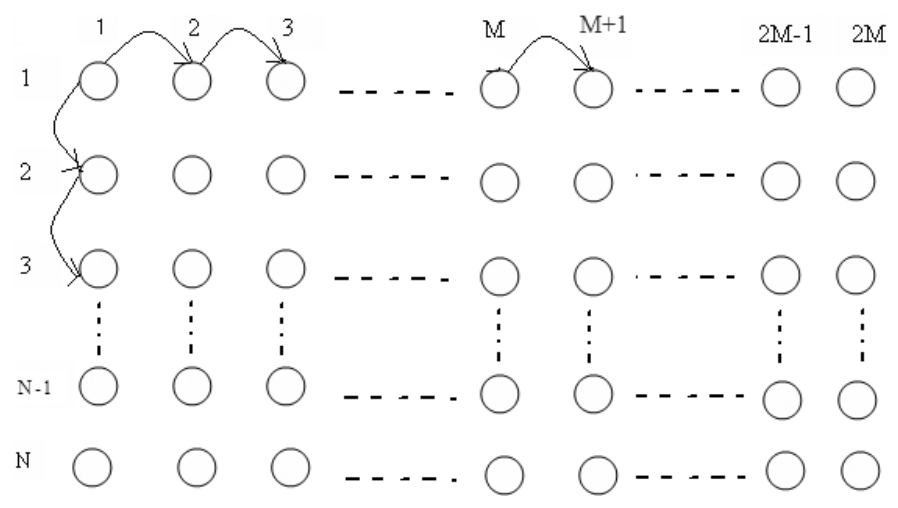

Fig. 1. Electrons moving in a lattice $N \times 2 M$.

scholars studying social enterprises ${ }^{3,14,15}$ thanks to appropriate incentive-mixes, different stakeholders in different sectors are put in contact and become straightly interdependent, just as different neighboring sides of the Möbius strip on which fermions are tunneling. Finally, CSR activities should strengthen stakeholders' adherence to the firm's mission, so that each stakeholder group can be seen as a replicated one working both for his specific sector and for the firm's mission. Figures 1 and 2 below shows the moves of the electrons in the Möbius strip before and after a twist. Specifically, we consider a rectangular lattice including $N \times 2 M$ sites (see Fig. 1). The electrons move in the longitudinal directions on $2 M$ wires and transverse directions on $N$ wires as indicated by the curved arrows.

The rectangle is then twisted by 180 degrees and its two sides are connected, such that the longitudinal wire 1 is attached to wire $2 M$; wire 2 is attached to wire $2 M-1$ and so on (see Fig. 2). The Möbius strip so constructed includes $M$ longitudinal wires

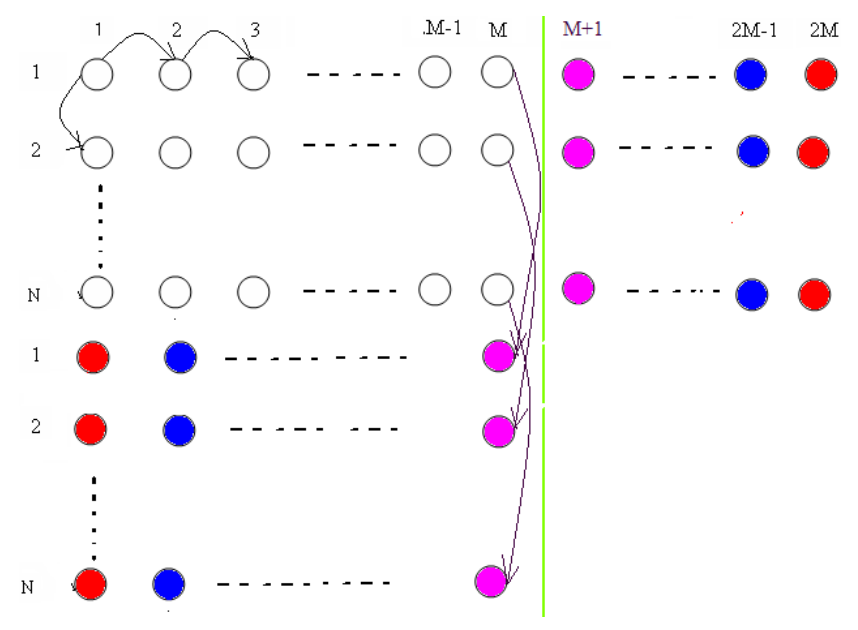

Fig. 2. The electrons moving in a Mobius strip. 
with $2 N$ sites on each wire. In other words, the columns, $M+1, M+2, \ldots, 2 M$ (the area behind the green line) are shifted to the bottom on the left, after the row $N$ in correspondence, respectively, of the column $1,2, \ldots, M$. Hence, more interactions are possible. For example the electrons in column $M$, which before the twist tunneled in the longitudinal direction in the adjacent $M+1$ column, now tunnel in the transverse direction in the same column $M$ but on the corresponding replicated element as well as tunnel in the transverse direction in the same column in the adjacent position.

It is possible to apply this construction to a SR company with $n=1, \ldots, N$ stakeholders or clusters of stakeholders and $m=1, \ldots, 2 M$ activities, where $m=$ $1, \ldots, M$ represent the traditional sectors of production of intermediate goods, necessary to produce the final good $M$; while $m=M+1, \ldots, 2 M$ are the specific activities devoted to the CSR.

Denoting by $0 \leq a_{m n}<1$, the contribution of stakeholder $n$ to sector $m$, like in a Möbius strip, also in a socially responsible firm the effects of a twist may be considered as the returns of CSR activities on its stakeholders and on firm production (see Fig. 3). These activities, therefore, amplify the crossed contributions of different stakeholders also operating in different sectors of the company. Figure 3 highlights the analogies between the move of the electrons in a Möbius strip with the $n$ stakeholders in a Company with $m$ sectors, after suitable investments in CSR have been carried out. This is the equivalent of Fig. 2 in the case of investments in CSR and in a matrix form. The electrons are replaced by stakeholder's contributions. The part of Fig. 2 after the green line corresponds to the part of the table after the dotted line and, as in Fig. 2, this part is shifted to the bottom on the left, after row $N$. Hence, stakeholder 1 contributes with $a_{11}$ to the production of sector 1 and with $a_{12}$ to the production of sector 2 and so on. Stakeholder 2 contributes with $a_{21}$ to the production of sector 1 and with $a_{22}$ to the production of sector 2 and so on. The same happens for all the other stakeholders. The value of $a_{12 M}$ measures the expected additional contribution that stakeholder 1 would give, thanks to the socially responsible activity $2 M$. The same holds true for the other socially

\begin{tabular}{|c|c|c|c|c|c|c|c|}
\hline & 1 & 2 & $\ldots$ & $\mathrm{M}$ & $M+1$ & $\ldots$ & $2 \mathrm{M}$ \\
\hline 1 & $\mathrm{a}_{11}$ & $\mathrm{a}_{12}$ & ......... & $\mathrm{a}_{1 \mathrm{M}}$ & $\mathrm{I}_{1 \mathrm{M}+1}$ & ........ & $\mathrm{a}_{12 \mathrm{M}}$ \\
\hline 2 & $\mathrm{a}_{21}$ & $\mathrm{a}_{22}$ & ……. & $\mathrm{a}_{2 \mathrm{M}}$ & $\mathrm{Ia}_{2 \mathrm{M}+1}$ & ......... & $\mathrm{a}_{22 \mathrm{M}}$ \\
\hline & ........ & & & & & & \\
\hline & & & & & 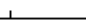 & & \\
\hline & & & & & 1 & & \\
\hline $\mathrm{N}$ & $\mathrm{a}_{\mathrm{N} 1}$ & $a_{\mathrm{N} 2}$ & & $\mathrm{a}_{\mathrm{NM}}$ & $\mathrm{a}_{\mathrm{NM}+1}$ & & $\mathrm{a}_{\mathrm{N} 2 \mathrm{M}}$ \\
\hline 1 & $\mathrm{a}_{12 \mathrm{M}}$ & $\mathrm{a}_{12 \mathrm{M}-1}$ & & $\mathrm{a}_{1 \mathrm{M}+1}$ & & & \\
\hline 2 & $\mathrm{a}_{22 \mathrm{M}}$ & $\mathrm{a}_{22 \mathrm{M}-1}$ & & $\mathrm{a}_{2 \mathrm{M}+1}$ & 1 & & \\
\hline . & ......... & & & & 1 & & \\
\hline- & & & & & 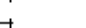 & & \\
\hline . & ......... & & & & 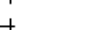 & & \\
\hline $\mathrm{N}$ & $a_{N 2 M}$ & $\mathrm{a}_{\mathrm{N} 2 \mathrm{M}-1}$ & & $\mathrm{a}_{\mathrm{NM}+1}$ & 1 & & \\
\hline
\end{tabular}

Fig. 3. The matrix of stakeholders'contributions in a CSR context. 
responsible activities, which are ordered in such a way that $2 M$ is more relevant for sector $1,2 M-1$ is more relevant for sector 2 ; etc. (for instance $2 M$ can be seen as the socially responsible activities dedicated to assure safe working conditions in sector $1 ; 2 M-1$ are the activities assuring safe working conditions in sector 2 and so on).

According to the above described analogies, analytically it is possible to devise a new cost-benefit model for CSR companies by using the Hubbard model for fermions, as in Ref. 49, where energy dissipation can be assimilated to production costs, while the crossed interaction-effects among fermions can approach the benefits associated to the joint contributions of $n$ stakeholders in $m$ sectors (for more details on how to derive this function, see Ref. 45).

By applying this model to a profit maximization problem of a company with only one class of stakeholders, i.e., $n$ workers, for given values of prices $p$ and wages $w$, we get

$$
H_{\mathrm{CSR}}=-\sum_{n=1}^{2 N} \sum_{m=1}^{M} c a+\sum_{n=1}^{2 N} \sum_{m=1}^{M}\left[t_{1}(1-\delta) a^{2}\right]+t_{2} \sum_{n=1}^{2 N} \sum_{m=1}^{M-1} a^{2}+\frac{t_{2}}{2} \sum_{n=1}^{2 N} a^{2},
$$

with $a \in \mathbb{R}$ and $0 \leq a<1$ for all $n=1, \ldots, N$ and $m=1, \ldots, M$, subject to the constraint of positive profits

$$
N M a[(p-w)-c] \geq 0 .
$$

The function is made up of four parts. (i) In the first (negative), ca represents the sum of the costs $c$ undergone by a company to finance socially responsible activities devoted to each $n$ in sector $m$; (ii) the second, called the neighborhood efficiency term, measures the gains associated to the crossed contributions of $n$ subjects (workers in our case) in sector $m$ with the nearest $n+1$ subject in the same sector; (iii) the third, called sector cooperation efficiency term, measures the gains associated to the crossed contributions of $n$ subjects in sector $m$ with the other subject types $n$ in the nearest sector $m+1$; (iv) the last part, called loyalty efficiency term, measures the gains associated to the increased productivity of each $n$ which contributes to the production of the final good $M$. Moreover we assume that $0 \leq \delta<1$ is the decay rate due to the possible effect of alienation (caused for instance by satiety, insufficient spare time, etc.). Finally $t_{1}$ and $t_{2}$ measure worker's sensitivities. They are related to the investments in CSR.

We assume that the workers' sensitivities $t_{1}$ and $t_{2}$ are equal and related to the investments in CSR through the function

$$
t=t_{1}=t_{2}=k(c a)^{\beta},
$$

where $k$ is a positive constant and $\beta \in \mathbb{R}$. Solving this maximization problem, we obtain:

$$
c^{1-\beta}=\frac{2 M}{\left[2 M(1-\delta)-2+a^{2}\right] k a^{1-\beta}},
$$


which, for $\beta>1$, increases for high values of $\delta$ and decreases for high values of $\beta$ and $M$.

These effects of $\beta, \delta$ and $M$ on the optimal value of $c$ are reversed when workers show low sensitivity to SR activities and $\beta<1$, while for $\beta=1$, it is always convenient to invest in CSR and the company chooses the optimal value of $c$ satisfying condition (2), as it can easily recoup CSR costs from the proportional increase in $t$ for $k \geq 1$.

These findings reveal that investments in CSR affect the firm's final performance, not only directly through the three above mentioned crossed-effects, but also trough the intermediate action of following factors: (a) workers' sensitivity, which makes convenient for the firm to develop CSR practices and to pay for the related expenses, since this process increases workers' productivity; (b) the alienation effect implies higher workers' aversion to job tasks and to the company culture or a greater preference for other activities, leisure or the family; (c) the effect of the number of sectors is controversial. First, if there are many sectors, the company can invest a limited amount for each of them, but on the other hand, social capital and workers' relations are of better quality in smaller sized firms, so that fewer additional responsible investments are required in smaller than in larger sized firms. As a result, what effect prevails in terms of efficiency depends on $\beta$.

\subsection{Hypotheses}

The theoretical model hypothesizes that CSR impacts first on organizational performance. Although several empirical papers assume that CSR improves performance, ${ }^{10,21,28,43,48}$ other empirical analyses find that socially friendly activities are not able to improve organizational performance. ${ }^{1,33}$ Taking into account the conflicting results reached by previous studies, we propose the following first working hypothesis:

H1: There is a positive and statistically significant effect of CSR investments on organizational performance.

If this hypothesis is not rejected, we proceed to analyze the role of the improvement in cooperative organizational patterns, as a consequence of CSR practices. In our empirical test, we do this by developing a SEM mediation model. The improvements in the relational context (indexed in the empirical part of the paper by time spent with colleagues, superiors and users) and the development of an incentive mix based on both monetary and nonmonetary rewards can improve the level of cooperation (for example, a high degree of involvement in decision-making and in the mission of the organization). Through the intermediate effect on cooperation, CSR influences performance, which is measured in our data by improved service quality and by achieved organizational and professional growth. CSR in terms of responsibility, reputation and trust, is also hypothesized to impact on worker satisfaction concerning professional growth and personal fulfilment and on worker extrinsic 
motivations concerning contractual conditions such as work hours, career prospects and job stability. In socially oriented organizational forms, organizational patterns informed by CSR criteria can interact in a complex way with workers drives, fulfilment, and behavior. ${ }^{13}$ The sign of these relations is hypothesized to be positive, since the better social standing of the organization is expected to positively reinforce motivation and improve fulfilment. The strength of the relation, however, needs to be enquired further. We also hypothesize that motivations and fulfilment influence organizational patterns based on cooperation. Workers that perceive organizational patterns informed by socially responsible objectives and procedures, and that are intrinsically and socially motivated, can react by looking for a higher degree of involvement, and increase their effort in terms of improved relations, pursuit of extra-role tasks and time spent with colleagues, superiors and users. The sign of these relations, though, needs further enquiry and explanation. Consequently, we propose the second working hypothesis:

H2: Cooperative organizational patterns exert a positive mediating effect between CRS practices and organizational performance.

We finally analyze the differential impact of a series of moderator variables: organizational size and socio-demographic features of the workforce.

H3: Organizational size and socio-demographic features of the workforce have a moderator effect on the relationship between CSR practices and organizational performance.

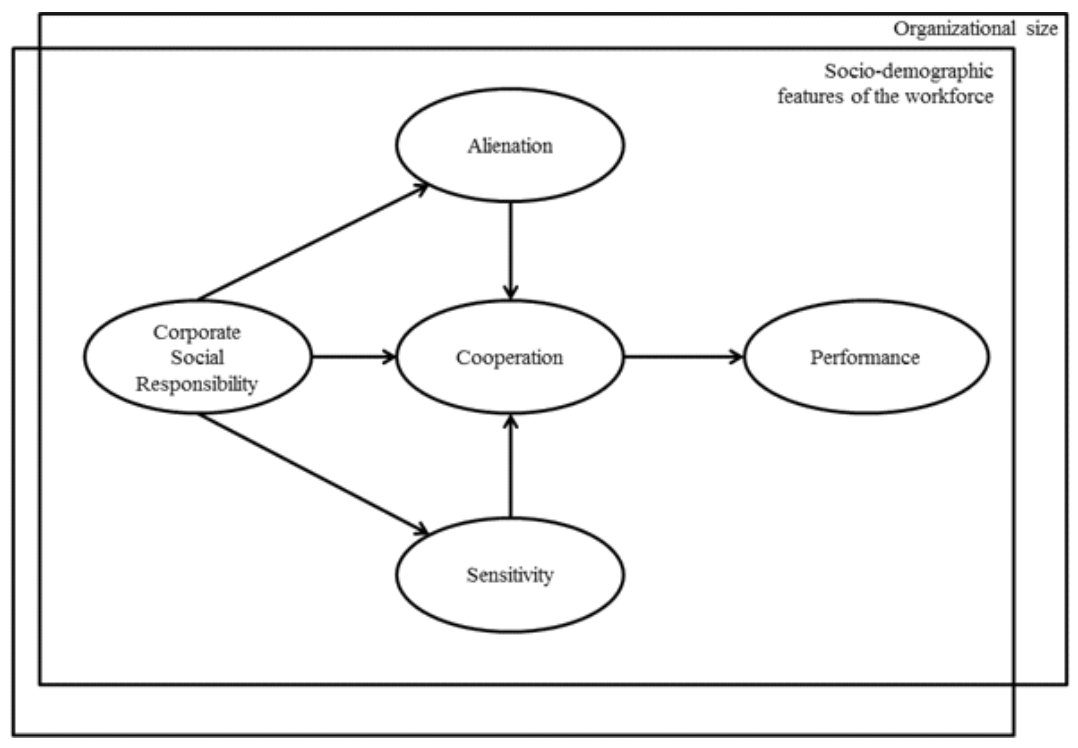

Fig. 4. SEM model: CSR as determinant of organizational performance. 
These hypotheses enable us to test both the direct effect flowing from CSR to cooperation patterns and performance, and the indirect effects mediated by the workers' motivations and fulfillment. Figure 4 substantially mimics the results and prepares the ground for the empirical test of the theoretical model. It shows how final firm performance is positively affected by the investments in CSR, not only directly but also through the effects of improved cooperation. These effects, in turn, depend on the mediating role of alienation and sensitivity, and can be affected by firm size and by the socio-demographic features of the workforce, which determine the optimal investment in CSR. This double influence is highlighted by the two overlapped rectangles.

\section{Empirical Analysis}

\subsection{The survey}

We can't recall the existence of any database including all the relevant behavioral dimensions of several stakeholder groups in several sectors, as identified in the theoretical model. However, when attention is restricted to workers as stakeholders of the organization in Italian social enterprises, represented by a national sample cooperative enterprises with a social aim (defined as Type A and Type B "Social Cooperatives" by the Italian legislation ${ }^{\mathrm{d}}$ ), it is possible to exploit the data collected by the ICSI 2007 survey (Survey on Italian Social Cooperatives). The survey is implemented by means of three different matched questionnaires compiled by paid workers, managers and representatives of the organization addressing 4134 paid workers, the matched 320 organizations employing them, and managers.

The three questionnaires are based on multiple-item questions, most of which are measured by Likert items. Questionnaires were administered by trained staff that supported the respondents on site, and compiled by workers in groups or taken at home and, in both cases, handed in anonymous envelopes, while late questionnaire were sent by post. This analysis uses mainly salaried-worker data to observe the worker's perspective on organizational processes. From an overview of individual profiles, we know that we are looking at workers in their 30s, mainly females $(74 \%)$, holding a permanent job positions $(80 \%)$. Education is college or university in $69 \%$ of cases. On average, the hourly wage was, in 2005, about 6.6

\footnotetext{
d The initial sample of 411 organizations was extracted from the 2003 census on social cooperatives (ISTAT, 2003), which counted 6168 active units (with at least one employee) at the national level. Social enterprises in Italy take, as a norm, the form of socially oriented co-operatives (so-called cooperative sociali), which are of two types in the Italian legislation: Type A delivers social services, while Type B is regulated by law to reintegrate weak individuals (the disabled, ex-drug addicted, ex-convicted, mentally ill, and long term unemployed) into the labor market. A nationwide representative sample was stratified on the basis of three parameters: (a) typology of cooperative (Type A and Type B); (b) geographic representativeness by province (Italy counts 20 regions and 109 provinces); (c) size (number of employees). About $85 \%$ of workers answered on average $90 \%$ of the 87 questions (56 single choice questions and 31 multiple choice questions).
} 
Euro, and tenure nearly six years. The average firm size is 33 employees, $78 \%$ of the involved organizations are Type A and $22 \%$ Type B cooperatives. A total of $62 \%$ are located in the North, $22 \%$ in the Centre, and $16 \%$ in the South of the country.

We use several questions included in the worker questionnaire, as they concern labor relations, involvement patterns, on the job satisfaction, and worker motivations. Questions related to CSR and firm performance are extracted, instead, from the organization questionnaire.

\subsection{Main variables}

The empirical model strictly corresponds to the theoretical one. In this latter model, performance represents the final outcome and is affected by the three typologies of cooperative interaction among the firm's stakeholders. The hypotheses in the empirical model aim at testing the effects of the three types of cooperation patterns on performance, as mediated by sensitivity (as represented by worker motivations) and alienation (as represented by different dimensions of job satisfaction). The sociodemographic features of the workforce and organizational size act as moderators.

\subsubsection{Performance}

The two indicators of performance are labelled PERF1 and PERF2 and are drawn from questions in the organization questionnaire. PERF1 is related to improvements in service quality over the past two to three years (ordered from 1 to 4 - "Worse" to "Much better", D40 in the questionnaire), while PERF2 is related to the current achieved condition of the organization in terms of professional growth, relational context and motivations of workers and managers (Likert scale 1 to 10, D66 in the questionnaire).

\subsubsection{Corporate social responsibility}

Likewise, CSR measures are drawn from the organization questionnaire and relate to the degree of social responsibility of the organization, as represented by perceived social responsibility towards its main stakeholders and towards public authorities and the community (ordered from 1 to 3 — "Not at all" to "Very much", D43), by the good reputation of the organization with the different stakeholder groups (dichotomous - "Low" and "High", D48), by trust relations between the cooperative and its stakeholders (ordered from 1 to 3 - "Not at all important" to "Very important", D50), and by organizational climate (ordered from 1 to 7, from "conflictual climate", to "community climate", D49).

e The three ICSI 2007 questionnaires (organizations, managers and paid workers), the dataset, log and do files of our SEM estimates are readily available upon request from the authors. 


\subsubsection{Cooperation, alienation and sensitivity of workers}

The variables concerning cooperation (indexed by time devoted to relations and worker involvement, DC), alienation (indexed by satisfaction, SAT) and sensitivity to the working of the organization (indexed by motivations, MOT) are measured by workers' self-reported, perceptions and evaluations. Cooperation is captured by three different measures: (i) cooperation among workers by the amount of time devoted to relations with other workers (e.g., with colleagues, superiors, the work group, and with volunteers; 1 to 5 Likert items, from "Never" to "Always", D29); (ii) cooperation with the cooperative, as represented by the development of interpersonal relations, and involvement in the mission and decision making processes of the cooperative (1 to 5 Likert items, from "Never" to "Always", D38); (iii) loyalty to the organization, as represented by the intention to stay in the same organization in the future (ordered from 1 to 4, from "Leave as soon as possible" to "Stay as long as possible", D49). The variables representing alienation relate to satisfaction with personal and professional growth, and autonomy (1 to 7 Likert items, D25). Finally, sensitivity to organizational dimensions is reflected in self-reported worker motivations, as related to extrinsic and contractual aspects, such as flexibility of working hours and job stability (1-12 Likert items).

\subsubsection{Socio-demographic features of the workforce and size of the organization}

We have introduced a final set of variables to moderate the postulated relationships. At the organizational level, we have studied the role of organizational size. The dimension of the workforce (including both members and employees) has been the classification criterion, distinguishing between small (below 15 workers), medium (between 16 and 50 workers) and large cooperatives (above 50 workers). Among the socio-demographic features of the workforce, we consider gender and education. The latter is sorted into five different educational degrees: elementary, intermediate, professional, high-school and university.

\subsection{Methodology}

Given the objective of this study, we start by carrying out a descriptive analysis of the observed variables in terms of their position measurements and use exploratory analysis techniques to evaluate their correlation matrix (Tables A.1 in the Appendix). We then use confirmatory factor analysis to examine the dimensional structure of the theoretical constructs involved in our hypothesis (Tables A.2 and A.3 in the Appendix). We subsequently analyze the respective measurement models in terms of reliability and validity. ${ }^{4,32}$ After these initial steps, we examine the measurement model and we estimate the factor scores, which are used in the structural model.

The structural model analyses the theoretical one and tests the working hypotheses. In the model, CSR measures affect (incentivize) cooperation (DC), which acts as intermediate organizational dimension through which the effect of CSR 
impacts on final performance. At the same time, the variables representing worker motivations (MOT) and worker satisfaction (SAT) are linked to CSR as they mimic the mediating role of worker sensitivity and alienation respectively on the CSR measures adopted by the organization. In order to evaluate the global fit of the model, we present different goodness of fit statistics and indices. ${ }^{11}$ This approach enables us to test the relationship between the performance variables and the different typologies of cooperative interaction among the firm's stakeholders through the analysis of direct, indirect and total effects in the mediation model.

Finally, the moderator effect of the socio-demographic features of the workforce and organizational size is conducted through a multi-group analysis. ${ }^{8,30}$ In this approach, we estimate the general model for the whole sample, assessing the individual significance of the direct, indirect, and total effects. Once the general model is tested, to assess whether socio-demographic variables and organizational size exert a moderating effect, we repeat the same process in each group. The moderating effect is assessed by analyzing the changes on the individual significance of each parameter.

This statistical approach enables us to obtain, test and estimate measurement and/or structural models based on robust statistics with multivariate non-normality and non-independence of observations. ${ }^{34}$ The general estimation method used is MLR (maximum likelihood robust to non-normality and nonindependence of observations) with the option complex due to the clustered structure of data. This approach is preferred to the two-level model option, since it takes into account stratification, non-independence of observations due to cluster sampling, and/or unequal probability of selection. ${ }^{34}$ We use the MPLUS 7.4 software. ${ }^{34}$

\subsection{Results}

Our structural equations model shows reasonable fit although this is slightly weak in the measurement model because of sample size and the number of variables (Appendix A). At any rate, fit indexes are above 0.90 and the RMSEA is lower than 0.08. The WRMR is close to 1 in both models. These values allow us to assess the economic relevance of the obtained results.

\subsubsection{Corporate social responsibility}

Table 1 shows the results of the structural model. CRS measures show a strong positive impact on performance. Direct effects on performance are positive and highly statistically significant. (PERF1-on-CSR:0.493; PERF2-on-CSR:0.717; $p$-value $<0.01)$. This result shows that social responsibility is an element that is able to improve service quality, and organizational and personal achievement.

When the indirect effects of CSR are added to the direct ones, the total effects are still stronger $(\mathrm{CSR} \rightarrow \mathrm{PERF} 1: 0.502 ; \mathrm{CSR} \rightarrow \mathrm{PERF} 2: 0.726 ; p$-value $<0.01)$ confirming the strong positive relation between socially responsible behaviors and organizational performance. As a consequence, it is not possible to reject hypothesis 
Table 1. Results of the structural equations model.

\begin{tabular}{|c|c|c|c|c|}
\hline & Estimate* & SE & $p$-value & $\mathrm{R}^{2}$ \\
\hline \multicolumn{5}{|l|}{ Direct effects } \\
\hline \multicolumn{5}{|l|}{ SAT on } \\
\hline CSR & 0.055 & 0.034 & 0.108 & 0.003 \\
\hline \multicolumn{5}{|l|}{ MOT on } \\
\hline CSR & 0.010 & 0.024 & 0.663 & 0.000 \\
\hline \multicolumn{5}{|l|}{ DC on } \\
\hline SAT & 0.913 & 0.004 & 0.000 & \multirow[t]{3}{*}{0.838} \\
\hline MOT & -0.033 & 0.008 & 0.000 & \\
\hline CSR & 0.026 & 0.011 & 0.020 & \\
\hline \multicolumn{5}{|l|}{ PERF1 on } \\
\hline $\mathrm{DC}$ & 0.092 & 0.057 & 0.104 & \multirow[t]{4}{*}{0.254} \\
\hline SAT & -0.059 & 0.055 & 0.282 & \\
\hline MOT & 0.013 & 0.027 & 0.623 & \\
\hline CSR & 0.493 & 0.045 & 0.000 & \\
\hline \multicolumn{5}{|l|}{ PERF2 on } \\
\hline $\mathrm{DC}$ & 0.207 & 0.046 & 0.000 & \multirow[t]{4}{*}{0.538} \\
\hline SAT & -0.128 & 0.041 & 0.002 & \\
\hline MOT & 0.021 & 0.021 & 0.302 & \\
\hline CSR & 0.717 & 0.030 & 0.000 & \\
\hline \multicolumn{5}{|l|}{ Indirect effects } \\
\hline $\mathrm{CSR} \rightarrow \mathrm{PERF} 1$ & 0.004 & 0.003 & 0.127 & \\
\hline $\mathrm{CSR} \rightarrow \mathrm{PERF} 2$ & 0.009 & 0.004 & 0.039 & \\
\hline \multicolumn{5}{|l|}{ Total effects } \\
\hline $\mathrm{CSR} \rightarrow \mathrm{PERF} 1$ & 0.502 & 0.045 & 0.000 & \\
\hline $\mathrm{CSR} \rightarrow \mathrm{PERF} 2$ & 0.726 & 0.029 & 0.000 & \\
\hline$\chi^{2}(5): 0.137$ & SEA: 0.00 & RMR: & ; CFI: & \\
\hline
\end{tabular}

*Standardized coefficients are reported PERF1 with PERF2: 0.271.

$H 1$, since a positive and statistically significant effect of CRS on organizational performance is detected.

\subsubsection{Cooperation, alienation and sensitivity of workers}

Concerning the effects of alienation, measured by the level of worker satisfaction (SAT), and the effect of sensitivity, measured by worker motivations (MOT), the former impacts positively (DC-on-SAT:0.913; $p$-value $<0.01$ ), while the latter negatively (DC-on-MOT:-0.033; $p$-value $<0.01$ ) on organizational patterns informed by cooperation (DC), represented by time spent in relations with colleagues, users and superiors, worker involvement in decision-making and in the mission of the organization, and stated loyalty towards the organization. These results show positive and reinforcing feedbacks between individual well-being, and organizational patterns that stabilize work relations and strengthen involvement. Increased satisfaction (SAT), which corresponds to a lower degree of alienation, can push workers to spend more time with colleagues and superiors, and to search for a higher degree of 
involvement. As for sensitivity, workers who are sensitive to the more extrinsic elements in the contractual relation (job stability, career and work hours' flexibility) would tend to pay less attention to organizational patterns informed by cooperation. This result is coherent with the idea, which is present in related literature, that intrinsic and social motivations are positively associated with worker wellbeing and involvement organizational patterns, while extrinsic motivations are negatively associated with the same elements. ${ }^{15}$ When the positive, though weakly significant, relation between CSR and satisfaction (SAT-ON-CSR:0.055; $p$-value $\approx 0.10$ ) and the strong positive relation between cooperation and the second index of performance achieved results (PERF2) — are considered together (PERF2-on-DC:0.207; $p$-value $<0.01$ ), a complete and positive pattern running all the way from CSR to satisfaction, cooperation and performance is reconstructed (CSR $\rightarrow$ PERF2:0.009; $p$-value $<0.05)$. As we shall see, this positive relation between satisfaction and cooperative organizational patterns more than compensates the negative direct relation between satisfaction and performance.

The analysis of the direct relation between motivations and fulfilment on the one hand, and performance on the other appears partially counter-intuitive. While motivations do not show strong direct impact on performance (PERF1-onMOT:0.013; PERF1-on-MOT:0.021; $p$-value >0.10), worker satisfaction shows stronger, but negative, impact (PERF1-on-SAT:-0.059; $p$-value $>0.10$; PERF2-onSAT:-0.128; $p$-value $<0.01)$. These results can be compared to several other results in the literature which, as a norm, rarely found a positive and/or strong relation between, on the one hand, job satisfaction and, on the other hand, job or organizational performance. ${ }^{4,17}$ Our results, which are statistically significant only in the case of the second index of performance (PERF2-achieved targets), may mean that satisfied workers do not feel the need to reach better results in terms of better relations, professional growth and motivation/participation. Increased satisfaction may indeed be directly connected with reduced effort, hence with a lower degree of achievement. ${ }^{18}$ Complementary, the requirement to increase effort and performance may reduce worker satisfaction, and this would be coherent with the assumptions of orthodox economics and agency theory, when satisfaction is taken as subjective selfreported measure of worker utility. ${ }^{17}$ On the other hand, the indirect effects running from CSR to performance and flowing through motivations, fulfilment and cooperative organizational patterns show positive impact on performance, even if they are not particularly strong (only the indirect effect on the second index of performance is statistically significant). These results highlight that, while satisfaction may not translate into better performance, the combination of intrinsic and social objectives, stronger motivations, fulfilment, and cooperative organizational patterns does. In other words, the negative effect of increased effort on satisfaction is more than compensated by the desire to pursue intrinsic and social objectives and by better involvement and relations. Therefore, there is a mediation effect of cooperation in the relation between CSR practices and organizational performance. This result is consistent with the second hypothesis $(H 2)$ of the theoretical model, which is not rejected. 
Therefore, there is a mediation effect of cooperation between CSR practices and organizational performance. This result is consistent with the second hypothesis of the theoretical model and does not allow us to reject $H 2$.

\subsubsection{Firm size}

We include firm size as moderator variable and comment in a detailed way the related results (Table 2), since this organizational dimension has central role in the theoretical model, and it served to stratify the original sample of surveyed organizations.

The difference between small and large size lies in the negative and statistically effect of CSR on satisfaction, which is positive and much stronger in smaller organizations (SAT-on-CSR:0.198; $p$-value $<0.01$ ). In large organizations, the relation between CSR and satisfaction is negative (SAT-on-CSR:-0.038; p-value $<0.01$ ), contrary to what is observed in the general sample. The negative relation between motivations and the formation of cooperative organizational patterns appears much weaker in small organizations than in the general sample (DC-on-MOT:-0.027; $p$-value $>0.10)$. Also, CSR impacts more heavily and positively on the formation of organizational patterns characterized by cooperation in small (DC-on-CSR:0.046; $p$-value $<0.05$ ) than in medium (DC-on-CSR:0.028; $p$-value $>0.10$ ) and large organizations (DC-on-CSR:0.014; $p$-value $>0.10$ ). These results would testimony the importance of interpersonal relations and knowledge in smaller organizations, which undergo weaker processes of formalization of organizational routines.

When performance is considered, it is important to notice that cooperation exerts a strong positive effect (PERF2-on-DC $>0 ; p$-value $<0.10)$ and satisfaction a negative effect on achieved results (PERF2) only in large organizations (PERF2-onSAT: $-0.197 ; p$-value $<0.05)$. In this case, it appears that the governance structure in terms of cooperative organizational patterns becomes more important in boosting performance as dimension increases. Large cooperatives are more structured, managed by professional managers and give workers more opportunities for professional growth. When these elements are conjugated with organizational patterns based on good relations and involvement, the positive effect on performance can become tangible. CSR always exerts strong positive effects on both indexes of performance in terms of both direct and total effects independently of size.

As related to the theoretical model, it predicts that the effect of size is controversial and that it essentially depends on worker sensitivity. In cases in which the effect of CSR is not very strong in large organizations, this weaker effect depends on the weak mediating role of alienation and sensitivity, which weaken the overall effect of CSR on performance. This is in line with our empirical results, since we find that the impact of CSR on satisfaction and motivations is stronger in smaller than in larger organizations, implying that the indirect (mediated) effect of CSR on performance is stronger as well. Indeed, the total impact of CSR on performance appears relatively stronger in smaller than in larger organizations. 


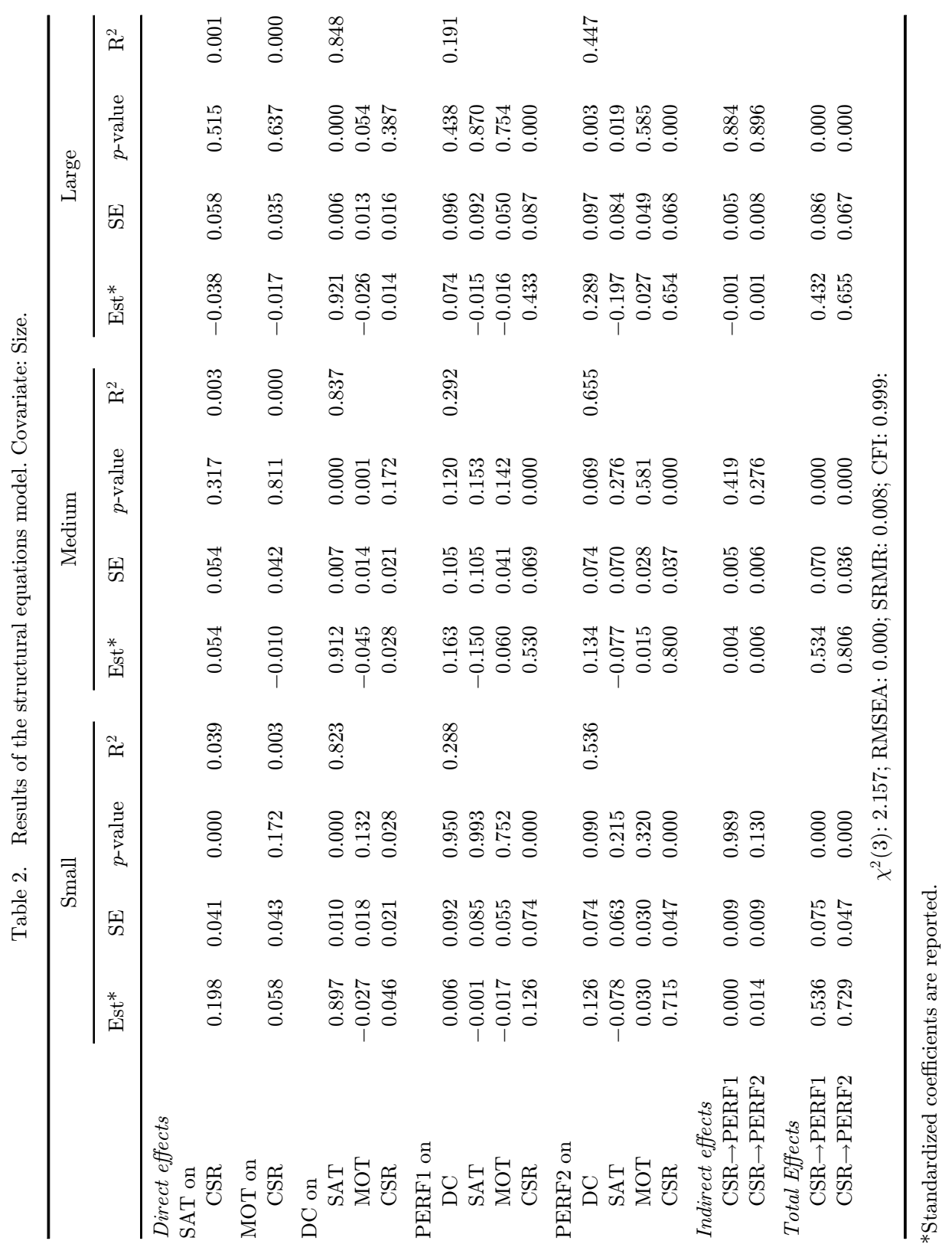




\subsubsection{Socio-demographic features of the workforce}

We describe here only the most relevant results concerning the main sociodemographic features of the workforce, taking into account education levels and gender. These results are detailed in Tables B.1 and B.2, Appendix B. The results concerning education evidence some relevant pattern: CSR exerts stronger influence on satisfaction in lower educated (Table B.1: SAT-ON-CSR:0.169; $p$-value $<0.05$ ) than in educated individuals (Table B.1: SAT-on-CSR:0.060; $p$-value $>0.10)$. This result can signal frustrated expectations about organizational goals in educated workers. The positive impact of CSR on motivations is weakly confirmed only in the case of graduated workers (Table B.1: MOT-on-CSR:0.059; $p$-value $\approx 0.10$ ), who may show better ability to adapt and be resilient to the organizational context. On the other hand, while the strong and positive relation between satisfaction and cooperative organizational patterns is confirmed for all education levels (Table B.1: DC-on-SAT $>0 ; p$-value $<0.01$ ), the negative relation between motivations and cooperative organizational patterns is confirmed only in the case of educated workers (Table B.1: DC-on-MOT:-0.050; $p$-value < 0.01). This evidence can signal, in educated workers, motivational burn out and frustrated expectations concerning involvement patterns and on the job relations. Finally, as concerns performance, its positive relation with cooperation is confirmed only in the case of educated workers (Table B.1: PERF1-on-DC:0.140; PERF2-onDC:0.246; $p$-value $<0.10)$, and this may signal better effectiveness, governance rules and involvement patterns in the case of individuals with better job positions, training and educational background.

When gender is considered, it is observed that the relation between CSR, satisfaction and cooperative organizational patterns is stronger in the case of women (Table B.2: SAT-on-CSR:0.06; $p$-value $<0.10$ ). This result can confirm indirectly the stronger sensitivity shown by women, when socially responsible aims and intrinsic motivations are considered. Notably, no relation is detected between CSR and cooperative organizational patterns in the case of men (Table B.2: DC-onCSR:-0.002; $p$-value $>0.10)$. The sign of the relations between performance in terms of achieved results, on the one hand, and satisfaction (negative sign) and cooperation (positive sign), on the other hand, is confirmed for both sexes but appears much stronger in the case of women than in the case of men.

After having observed differential impacts due to organizational size and to the socio-demographic features of the workforce, we can state that these elements can redefine the model parameters, that is, they have a moderator effect on the relationship between CSR practices and organizational performance. Hypothesis $H 3$ cannot be refused too.

As final comments to the empirical analysis, we evidence that the main message emerging from the analysis concerns the positive relation between CSR and performance in the context of Italian social cooperatives. This relation is exerted both directly through the positive effect of responsible behavior, especially towards users 
and the local community, trust and reputation, on the targets reached by the organization, or indirectly through improved cooperation in terms of relational context, satisfaction, and involvement in the workplace.

These empirical arguments are perfectly coherent with the theoretical hypotheses underpinning our model, since CSR impacts positively on cooperation, and CSR jointly with cooperation positively impacts on the second index of performance and, more weakly, also on the first index of performance. This confirms our working hypotheses. The positive effect of satisfaction on cooperation signals a reduced level of worker alienation, meaning that satisfied workers would contribute more to organizational patterns characterized by improved relations and involvement.

\section{Conclusion}

Within a CSR framework of analysis, all socio-economic activities generate interlinked relationships, which can be better interpreted and analyzed by resorting to the complex system approach. By following the theoretical model by, see Ref. 45 which relies on basic analogies with the physics model of electrons traveling on a Mobius strip, it is possible to account, both theoretically and empirically, for the effects of increased cooperation among stakeholders due to their investments in CSR. In this work, by using worker data on labor relations drawn from a large sample of Italian social enterprises (social cooperatives), we empirically test the existence and the effects of these interactions. In particular, in accordance with our theoretical model, we ask whether firm's performance is correlated with its stakeholders' investments in CSR through their effects on cooperation among the stakeholders and on loyalty towards the organization. Again following the theoretical model, we also enquire the mediating role of workers' sensitivity, proxied by motivations, of their degree of alienation, proxied negatively by higher on-the-job satisfaction, and of firm size.

To achieve our results, we use mathematical models that are seldom applied in the social sciences, and structural equation modeling to test and quantify the impact of CSR on firm performance. This approach represents an initial, but effective attempt to accomplish a rigorous analysis of much debated questions, which did not find settled answers to date. Also, we submit that our main results concerning CSR and the role of co-operative governance can represent important tools in designing new governance solutions, managerial practices, and training courses, informed by advanced knowledge about the relation between the social behavior of organizations, and their positive external effects which, as we show, are not in contrast with better organizational performance. The implications of our results are coherent with our theoretical premises, confirming that the behavior and performance of cooperatives enterprises can't be described by using the traditional profit function because more interactions and complex relationships among agents should be taken into account.

Our empirical test concerns CSR as embodied in labor relation in the Italian social economy. More specifically, we use worker data drawn from social cooperatives 
operating in the social service sector. In this kind of organization, CSR is to be considered a crucial organizational dimension and a strategic asset, since it enters the social and reputational capital on which the activity of the organization is based. Consequently, our result need to be considered first and formost as specific to the working of third sector and social economy organizations.

Organizations that consider CSR as a strategic asset can invest more than average in such an asset. Higher investments in CSR can generate stronger and more effective impact on performance. The social economy has a limited, but relevant effect on the outcomes of most advanced economy. The weight of the nonprofit sector is estimated to be close or higher than 10\% of GDP in several advanced countries, and social economy organizations create a higher than average percentage of new jobs in the same countries. Furthermore, social economy organizations are reported to be able to produce public, semi-public, and meritorious goods and services, implying increased positive external effects and reduced social costs. ${ }^{14}$ In most circumstances the public and the private sectors are not able to do so in the same effective way. ${ }^{46}$

The value of the study can be considered high when the economics of the third sector is considered. Its relevance is more limited, but not absent, for the economy at large and other types of business organizations. Indeed, important contributions have been underlying the positive relation between CSR and firm performance in all business enterprises, ${ }^{36}$ and this makes us confident about the possibility to replicate similar tests in different sectors and organizational contexts. We can hypothesize that the model can be generalized and applied to contexts characterized by more complex interactions than what is implied by the model of the self-interested homo economics. For instance, this is the case in cooperation games, in reciprocating behaviors (see Ref. 16) in the vote-with-the-wallet game ${ }^{7}$ and, in more general terms, in all social and organizational contexts in which accumulated social capital is high. ${ }^{41}$ In all these cases, people interact having as their objective the common good, and not only their own welfare, aware that the wellbeing of everyone else affects, in turn, their own welfare, increasing this way also the shareable surplus. Finally, we also show that to stipulate cooperation, important investments and costs, both monetary and in terms of time expensive and cultural activities, are required. To the best of our knowledge, our approach represents the first attempt to theoretically model and empirically test a new cost-benefit function analyzing such organizational behaviors in the presence of deep interactions among the organization and its stakeholders. Such dimensions are not dealt with in the traditional profit function. Clearly, more research and survey work are needed to improve the reach, width and validity of our work, for example concerning further interactions and effects in the theoretical model. Future empirical research can use larger samples and consider additional organizational and social contexts to study crossed contributions and impacts among different stakeholders and sectors. Comparative studies would be needed as well, since different organizational forms can invest differently in CSR, this way obtaining different impacts on performance. 


\section{Acknowledgments}

The survey on which the empirical analysis is based was carried out between March 2004 and February 2008 in Italy by five research units at the Universities of Brescia, Milan, Naples, Reggio Calabria and Trento. The research was supported by (1) a grant of the Italian Ministry for University and Scientific Research based on the national research project (PRIN) titled: "The Economic Role of Nonprofit Organizations: New Theoretical Developments and Empirical Tests"; (2) by a grant of the Foundation of the Saving Bank of the Lombard Provinces (Ca.Ri.P.Lo. Foundation); (3) by the personnel at ISSAN-EURICSE (European Research Institute for Cooperative and Social Enterprises) in Trento. This work is part of EURICSE (European Research Institute on Cooperative and Social Enterprises) project "Survey on Italian Social Cooperatives" (SISC/ICSI survey). We wish to thank Carlo Borzaga, principal investigator of the ICSI research program, Maurizio Carpita for methodological development, and Sara Depedri, Marica Manisera e Elena Poli for data handling. We would like to also thank CREVALOR (S17) research group for its support in the elaboration of this paper, FPU Financial Program (FPU 13/02481) and MINECO project (ECO2016-74920-C2-1-R).

\section{Appendix A. Descriptive Statistics and Measurement Models}

Table A.1. Descriptive statistics.

\begin{tabular}{lllllll}
\hline Dimension & Abr & \multicolumn{1}{c}{ Item } & Mean & SE & Max & Min \\
\hline PERF1 & A3 & Service quality relative to similar organizations & 3.122 & 0.691 & 5 & 2 \\
& A4 & Service quality relative to two years ago & 3.062 & 0.549 & 5 & 1 \\
& A5 & Service quality relative to five years ago & 3.463 & 0.667 & 5 & 1 \\
PERF2 & A8 & Target reached: good relations among workers & 7.376 & 1.137 & 10 & 5 \\
& A9 & Target reached: relations between workers and their superiors & 7.292 & 1.243 & 10 & 1 \\
& A10 & Target reached: professional skills and competencies of managers & 7.755 & 1.213 & 10 & 1 \\
& A11 & Target reached: professional skills and competencies of workers & 7.668 & 1.106 & 10 & 3 \\
& A13 & Target reached: ability to work in team & 7.343 & 1.452 & 10 & 3 \\
& A15 & Target reached: internal communication/relations & 6.993 & 1.333 & 10 & 2 \\
& A17 Target reached: motivation/participation of managers & 8.093 & 1.271 & 10 & 1 \\
& A18 Target reached: motivation/paticiption of workers & 7.408 & 1.379 & 10 & 1 \\
CSR1 & A20 Cooperative responsible towards service beneficiaries & 2.855 & 0.355 & 3 & 2 \\
& A21 Cooperative responsible towards local community & 2.432 & 0.554 & 3 & 1 \\
& A22 Cooperative responsible towards workers & 2.833 & 0.373 & 3 & 2 \\
& A23 Cooperative responsible towards private financial supporters & 1.980 & 0.719 & 3 & 1 \\
& A24 Cooperative responsible towards public institutions & 2.346 & 0.570 & 3 & 1 \\
CSR2 & A25 Reputation of the cooperative towards users & 5.746 & 0.906 & 7 & 4 \\
& A26 & Reputation of the cooperative towards other organizations in & 5.688 & 0.932 & 7 & 1 \\
& & the sector & & & & \\
& A27 Reputation of the cooperative towards local community & 5.476 & 0.932 & 7 & 3 \\
& A29 Reputation of the cooperative towards public institutions & 5.639 & 0.888 & 7 & 2 \\
& A31 Reputation of the cooperative towards public administration & 5.449 & 1.048 & 7 & 1 \\
\hline
\end{tabular}


Table A.1. (Continued)

\begin{tabular}{|c|c|c|c|c|c|c|}
\hline Dimension & Abr & Item & Mean & $\mathrm{SE}$ & Max & Min \\
\hline \multirow[t]{4}{*}{ CSR3 } & A35 & Trust between the cooperative and public administration & 5.989 & 1.088 & 7 & 1 \\
\hline & A36 & Trust between the cooperative private suppliers & 5.177 & 1.240 & 7 & 1 \\
\hline & $\mathrm{A} 41$ & Trust between the cooperative in general & 5.620 & 1.130 & 7 & 1 \\
\hline & A33 & Organizational climate & 4.370 & 0.973 & 6 & 1 \\
\hline \multirow[t]{4}{*}{ SAT } & $\mathrm{A} 42$ & W25_1 Satisfaction with professional growth and training & 4.645 & 1.586 & 7 & 1 \\
\hline & $\mathrm{A} 43$ & W25_2 Satisfaction with on the job autonomy and independence & 5.072 & 1.475 & 7 & 1 \\
\hline & A44 & W25_3 Satisfaction with past and perspective career advancement & 3.854 & 1.700 & 7 & 1 \\
\hline & $\mathrm{A} 45$ & W25_4 Personal fulfilment & 4.932 & 1.620 & 7 & 1 \\
\hline \multirow[t]{3}{*}{ MOT } & A49 & W54_4 Flexibility of work hours & 8.010 & 3.093 & 12 & 1 \\
\hline & A51 & W54_6 Personal accomplishment and career prospects & 8.374 & 3.126 & 12 & 1 \\
\hline & $\mathrm{A} 52$ & W54_7 Job stability & 9.523 & 2.794 & 12 & 1 \\
\hline \multirow[t]{3}{*}{ DC1 } & A59 & W29_2 Time devoted to relations with colleagues & 3.997 & 0.880 & 5 & 1 \\
\hline & A60 & W29_3 Time devoted to relations with superiors & 3.397 & 1.078 & 5 & 1 \\
\hline & A62 & W29_5 Time devoted to relations with institutions and users & 2.757 & 1.194 & 5 & 1 \\
\hline \multirow[t]{7}{*}{$\mathrm{DC} 2$} & A64 & W38_1 Satisfaction of needs as worker & 3.819 & 0.969 & 5 & 1 \\
\hline & A65 & W38_2 Job stability & 3.821 & 1.069 & 5 & 1 \\
\hline & A66 & W38_3 Other material incentives & 2.974 & 1.198 & 5 & 1 \\
\hline & A67 & W38_4 Interpersonal relations & 3.273 & 1.079 & 5 & 1 \\
\hline & A69 & W38_6 Involvement in the mission of the organization & 3.127 & 1.243 & 5 & 1 \\
\hline & $\mathrm{A} 70$ & W38_7 Involvement in decision making & 2.883 & 1.267 & 5 & 1 \\
\hline & & $\begin{array}{l}\text { W38_8 Organization of cultural events with colleagues and } \\
\text { associates }\end{array}$ & 2.644 & 1.147 & 5 & 1 \\
\hline
\end{tabular}

Table A.2. Results of the measurement equations models. Cooperatives.

\begin{tabular}{|c|c|c|c|c|c|c|c|}
\hline & & Estimate* & SE & $p$-value & Alfa & AVE & $\mathrm{CRC}$ \\
\hline \multicolumn{8}{|c|}{ PERF1 by } \\
\hline A3 & $\begin{array}{l}\text { Service quality relative to similar organiza- } \\
\text { tions }\end{array}$ & 0.690 & 0.079 & 0.000 & 0.518 & 0.564 & 0.750 \\
\hline A4 & Service quality relative to two years ago & 0.763 & 0.060 & 0.000 & & & \\
\hline A5 & Service quality relative to five years ago & 0.796 & 0.060 & 0.000 & & & \\
\hline \multicolumn{8}{|c|}{ PERF2 by } \\
\hline A8 & $\begin{array}{l}\text { Targets reached: good relations among } \\
\text { workers }\end{array}$ & 0.797 & 0.027 & 0.000 & 0.917 & 0.643 & 0.801 \\
\hline A9 & $\begin{array}{l}\text { Targets reached: relations between workers } \\
\text { and their superiors }\end{array}$ & 0.814 & 0.023 & 0.000 & & & \\
\hline A10 & $\begin{array}{l}\text { Targets reached: professional skills and } \\
\text { competencies of managers }\end{array}$ & 0.834 & 0.022 & 0.000 & & & \\
\hline A11 & $\begin{array}{l}\text { Targets reached: professional skills and } \\
\text { competencies of workers }\end{array}$ & 0.806 & 0.024 & 0.000 & & & \\
\hline A13 & Targets reached: ability to work in team & 0.772 & 0.028 & 0.000 & & & \\
\hline $\mathrm{A} 15$ & $\begin{array}{l}\text { Targets reached: internal communication/ } \\
\text { relations }\end{array}$ & 0.732 & 0.027 & 0.000 & & & \\
\hline A17 & $\begin{array}{l}\text { Targets reached: motivation/participation } \\
\text { of managers }\end{array}$ & 0.776 & 0.026 & 0.000 & & & \\
\hline
\end{tabular}


Table A.2. (Continued)

\begin{tabular}{|c|c|c|c|c|c|c|c|}
\hline & & Estimate* & $\mathrm{SE}$ & $p$-value & Alfa & AVE & $\mathrm{CRC}$ \\
\hline A18 & $\begin{array}{l}\text { Targets reached: motivation/paticiption of } \\
\text { workers }\end{array}$ & 0.876 & 0.021 & 0.000 & & & \\
\hline \multicolumn{8}{|l|}{ CSR1 by } \\
\hline A20 & $\begin{array}{l}\text { Cooperative responsible towards service } \\
\text { beneficiaries }\end{array}$ & 0.832 & 0.091 & 0.000 & 0.648 & 0.480 & 0.680 \\
\hline $\mathrm{A} 21$ & $\begin{array}{l}\text { Cooperative responsible towards local com- } \\
\text { munity }\end{array}$ & 0.814 & 0.067 & 0.000 & & & \\
\hline $\mathrm{A} 22$ & Cooperative responsible towards workers & 0.568 & 0.104 & 0.000 & & & \\
\hline $\mathrm{A} 23$ & $\begin{array}{l}\text { Cooperative responsible towards private } \\
\text { financial supporters }\end{array}$ & 0.503 & 0.079 & 0.000 & & & \\
\hline $\mathrm{A} 24$ & $\begin{array}{l}\text { Cooperative responsible towards public } \\
\text { institutions }\end{array}$ & 0.674 & 0.075 & 0.000 & & & \\
\hline \multicolumn{8}{|l|}{ CSR2 by } \\
\hline $\mathrm{A} 25$ & Reputation of the cooperative towards users & 0.735 & 0.036 & 0.000 & 0.823 & 0.584 & 0.762 \\
\hline A 26 & $\begin{array}{l}\text { Reputation of the cooperative towards other } \\
\text { organizations in the sector }\end{array}$ & 0.676 & 0.043 & 0.000 & & & \\
\hline $\mathrm{A} 27$ & $\begin{array}{l}\text { Reputation of the cooperative towards local } \\
\text { community }\end{array}$ & 0.790 & 0.033 & 0.000 & & & \\
\hline A 29 & $\begin{array}{l}\text { Reputation of the cooperative towards } \\
\text { public institutions }\end{array}$ & 0.840 & 0.027 & 0.000 & & & \\
\hline A31 & $\begin{array}{l}\text { Reputation of the cooperative towards } \\
\text { public administration }\end{array}$ & 0.769 & 0.031 & 0.000 & & & \\
\hline \multicolumn{8}{|l|}{ CSR3 by } \\
\hline A35 & $\begin{array}{l}\text { Trust between the cooperative and public } \\
\text { administration }\end{array}$ & 0.525 & 0.066 & 0.000 & 0.515 & 0.262 & 0.501 \\
\hline A36 & $\begin{array}{l}\text { Trust between the cooperative private } \\
\text { suppliers }\end{array}$ & 0.366 & 0.066 & 0.000 & & & \\
\hline A41 & Trust between the cooperative in general & 0.658 & 0.053 & 0.000 & & & \\
\hline A33 & Organizational climate & 0.454 & 0.080 & 0.000 & & & \\
\hline \multicolumn{8}{|l|}{ CRS by } \\
\hline CSR1 & Responsible & 0.625 & 0.070 & 0.000 & 0.862 & 0.589 & 0.761 \\
\hline CSR2 & Reputation & 0.839 & 0.059 & 0.000 & & & \\
\hline CSR3 & Trust and climate & 0.820 & 0.070 & 0.000 & & & \\
\hline \multicolumn{8}{|c|}{ PERF1 with } \\
\hline PERF2 & Performance 2 & 0.416 & 0.061 & 0.000 & & & \\
\hline CSR & Corporate Social Responsibility & 0.373 & 0.062 & 0.000 & & & \\
\hline \multicolumn{8}{|c|}{ PERF2 with } \\
\hline CSR & Corporate Social Responsibility & 0.623 & 0.045 & 0.000 & & & \\
\hline
\end{tabular}

*Standardized coefficients are reported. 
Table A.3. Results of the measurement equations models. Workers.

\begin{tabular}{|c|c|c|c|c|c|c|c|}
\hline & & Estimate* & SE & $p$-value & Alfa & AVE & $\mathrm{CRC}$ \\
\hline \multicolumn{8}{|l|}{ SAT by } \\
\hline A 42 & $\begin{array}{l}\text { W25_1 Satisfaction with professional } \\
\text { growth and training }\end{array}$ & 0.789 & 0.009 & 0.000 & 0.809 & 0.560 & 0.747 \\
\hline A 43 & $\begin{array}{l}\text { W25_2 Satisfaction with on the job } \\
\text { autonomy and independence }\end{array}$ & 0.680 & 0.011 & 0.000 & & & \\
\hline A44 & $\begin{array}{l}\text { W25_3 Satisfaction with past and } \\
\text { perspective career advancement }\end{array}$ & 0.757 & 0.010 & 0.000 & & & \\
\hline A 45 & W25_4 Personal fulfilment & 0.761 & 0.009 & 0.000 & & & \\
\hline \multicolumn{8}{|l|}{ MOT by } \\
\hline $\mathrm{A} 49$ & W54_4 Flexibility of work hours & 0.458 & 0.021 & 0.000 & 0.522 & 0.274 & 0.520 \\
\hline A51 & $\begin{array}{l}\text { W54_6 Personal accomplishment and } \\
\text { career prospects }\end{array}$ & 0.506 & 0.021 & 0.000 & & & \\
\hline A52 & W54_7 Job stability & 0.597 & 0.024 & 0.000 & & & \\
\hline \multicolumn{8}{|l|}{ DC1 by } \\
\hline A59 & $\begin{array}{l}\text { W29_2 Time devoted to relations with } \\
\text { colleagues }\end{array}$ & 0.514 & 0.022 & 0.000 & 0.583 & 0.352 & 0.582 \\
\hline A60 & $\begin{array}{l}\text { W29_3 Time devoted to relations with } \\
\text { superiors }\end{array}$ & 0.745 & 0.023 & 0.000 & & & \\
\hline A62 & $\begin{array}{l}\text { W29_5 Time devoted to relations with } \\
\text { institutions and users }\end{array}$ & 0.488 & 0.026 & 0.000 & & & \\
\hline \multicolumn{8}{|l|}{ DC2 by } \\
\hline A64 & W38_1 Satisfaction of needs as worker & 0.546 & 0.017 & 0.000 & 0.821 & 0.381 & 0.614 \\
\hline A65 & W38_2 Job stability & 0.522 & 0.016 & 0.000 & & & \\
\hline A66 & W38_3 Other material incentives & 0.651 & 0.014 & 0.000 & & & \\
\hline A 67 & W38_4 Interpersonal relations & 0.707 & 0.012 & 0.000 & & & \\
\hline A69 & $\begin{array}{l}\text { W38_6 Involvement in the mission of the } \\
\text { organization }\end{array}$ & 0.669 & 0.014 & 0.000 & & & \\
\hline A70 & W38_7 Involvement in decision making & 0.657 & 0.015 & 0.000 & & & \\
\hline A71 & $\begin{array}{l}\text { W38_8 Organization of cultural events } \\
\text { with colleagues and associates }\end{array}$ & 0.543 & 0.016 & 0.000 & & & \\
\hline \multicolumn{8}{|c|}{ 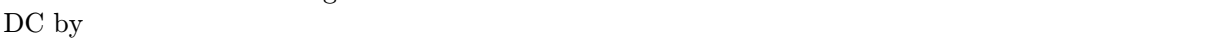 } \\
\hline DC1 & LD29 & 0.483 & 0.022 & 0.000 & 0.656 & 0.454 & 0.653 \\
\hline DC2 & LD38 & 0.822 & 0.025 & 0.000 & & & \\
\hline \multicolumn{8}{|l|}{ SAT with } \\
\hline MOT & L54 & 0.016 & 0.028 & 0.575 & & & \\
\hline $\mathrm{DC}$ & $\mathrm{DC}$ & 0.795 & 0.027 & 0.000 & & & \\
\hline \multicolumn{8}{|l|}{ MOT with } \\
\hline $\mathrm{DC}$ & $\mathrm{DC}$ & -0.011 & 0.034 & 0.747 & & & \\
\hline & $\chi^{2}(114) 916.379 ;$ RMSEA: 0.04 & NRMR: 1. & $78 ; \mathrm{C}$ & I: 0.928 & & & \\
\hline
\end{tabular}

*Standardized coefficients are reported. 


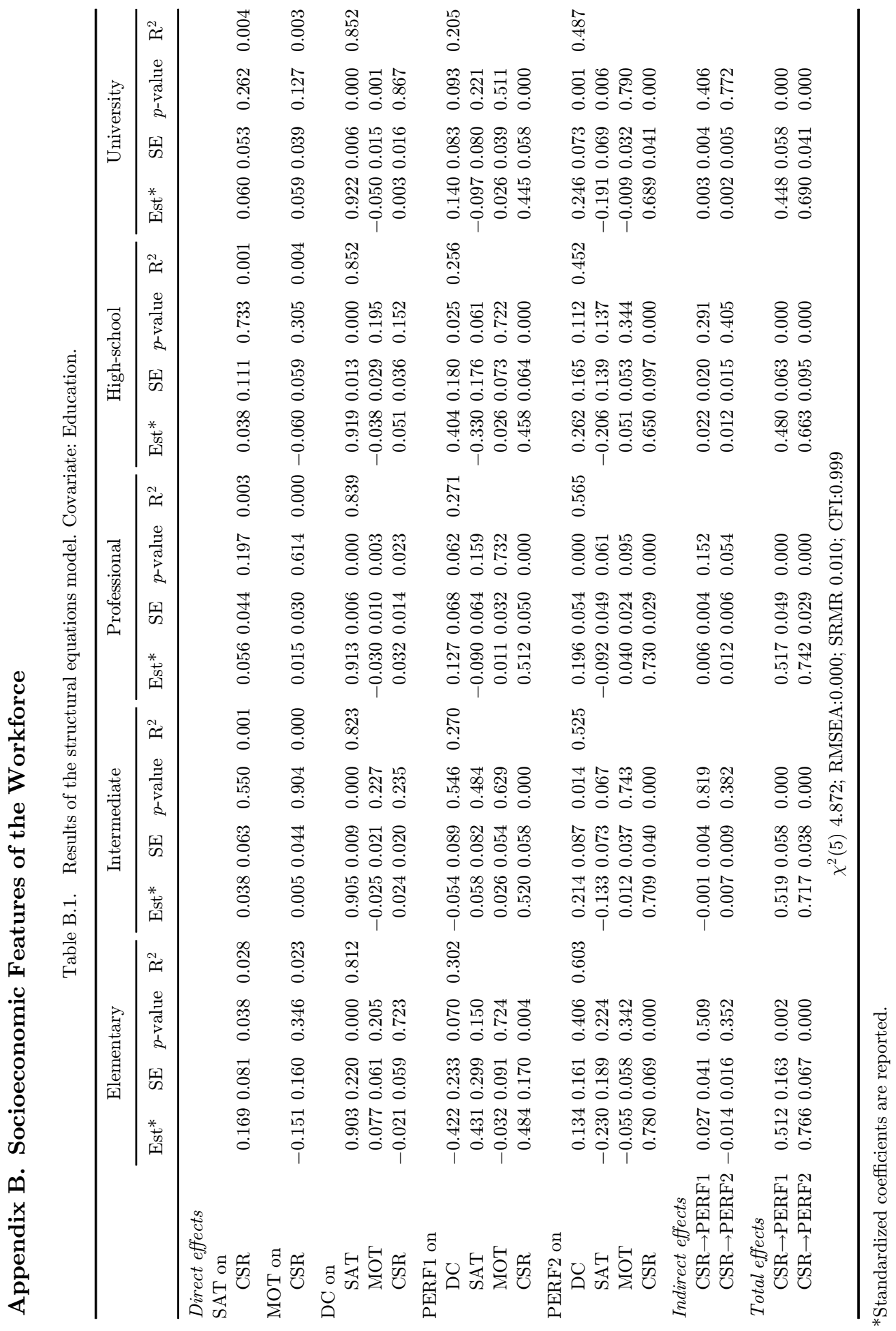


Table B.2. Results of the structural equations model. Covariate: Gender.

\begin{tabular}{|c|c|c|c|c|c|c|c|c|}
\hline & \multicolumn{4}{|c|}{ Male } & \multicolumn{4}{|c|}{ Female } \\
\hline & Est* & $\mathrm{SE}$ & $p$-value & $\mathrm{R}^{2}$ & Est* & SE & $p$-value & $\mathrm{R}^{2}$ \\
\hline \multicolumn{9}{|l|}{ Direct effects } \\
\hline \multicolumn{9}{|l|}{ SAT on } \\
\hline CSR & 0.042 & 0.051 & 0.404 & 0.002 & 0.060 & 0.036 & 0.091 & 0.004 \\
\hline \multicolumn{9}{|l|}{ MOT on } \\
\hline CSR & -0.010 & 0.037 & 0.793 & 0.000 & 0.016 & 0.026 & 0.543 & 0.000 \\
\hline \multicolumn{9}{|l|}{$\mathrm{DC}$ on } \\
\hline SAT & 0.923 & 0.006 & 0.000 & 0.854 & 0.909 & 0.005 & 0.000 & 0.833 \\
\hline MOT & -0.038 & 0.014 & 0.006 & & -0.031 & 0.010 & 0.002 & \\
\hline CSR & -0.002 & 0.017 & 0.927 & & 0.036 & 0.012 & 0.003 & \\
\hline \multicolumn{9}{|l|}{ PERF1 on } \\
\hline $\mathrm{DC}$ & 0.078 & 0.081 & 0.337 & 0.220 & 0.092 & 0.062 & 0.141 & 0.269 \\
\hline SAT & -0.092 & 0.073 & 0.209 & & -0.043 & 0.060 & 0.473 & \\
\hline MOT & -0.002 & 0.037 & 0.957 & & 0.019 & 0.030 & 0.528 & \\
\hline CSR & 0.468 & 0.050 & 0.000 & & 0.509 & 0.049 & 0.000 & \\
\hline \multicolumn{9}{|l|}{ PERF2 on } \\
\hline $\mathrm{DC}$ & 0.131 & 0.066 & 0.047 & 0.588 & 0.234 & 0.050 & 0.000 & 0.521 \\
\hline SAT & -0.065 & 0.056 & 0.240 & & -0.149 & 0.046 & 0.001 & \\
\hline MOT & 0.007 & 0.023 & 0.758 & & 0.027 & 0.024 & 0.250 & \\
\hline CSR & 0.761 & 0.033 & 0.000 & & 0.700 & 0.032 & 0.000 & \\
\hline \multicolumn{9}{|l|}{ Indirect effects } \\
\hline $\mathrm{CSR} \rightarrow \mathrm{PERF} 1$ & -0.001 & 0.002 & 0.609 & & 0.006 & 0.004 & 0.110 & \\
\hline $\mathrm{CSR} \rightarrow \mathrm{PERF} 2$ & 0.002 & 0.005 & 0.642 & & 0.013 & 0.005 & 0.019 & \\
\hline \multicolumn{9}{|l|}{ Total effects } \\
\hline $\mathrm{CSR} \rightarrow \mathrm{PERF} 1$ & 0.467 & 0.050 & 0.000 & & 0.515 & 0.049 & 0.000 & \\
\hline $\mathrm{CSR} \rightarrow \mathrm{PERF} 2$ & 0.763 & 0.032 & 0.000 & & 0.712 & 0.031 & 0.000 & \\
\hline & 1.446 & MSE & 000; SR & $\mathrm{R} 0.0$ & CFI:0.9 & & & \\
\hline
\end{tabular}

*Standardized coefficients are reported.

\section{References}

1. B. Y. Abiodun, The impact of corporate social responsibility on firms' profitability in Nigeria, Eur. J. Econ. Financ. Adm. Sci. 45(1) (2012) 39-50.

2. M. Aoki, The Cooperative Game Theory of the Firm (Cambridge University Press, Cambridge, MA, 1984).

3. A. Bacchiega and C. Borzaga, Social enterprises as incentive structures: An economic analysis, in The Emergence of Social Enterprise, eds. C. Borzaga and J. Defourny (Routledge, New York, 2001).

4. R. P. Bagozzi, Causal Models in Marketing (John Wiley and Sons, New York, 1980).

5. L. Becchetti, A. Palestini, N. Solferino and M. E. Tessitore, The socially responsible choice in a duopolistic market: A dynamic model of ethical product differentiation, Econ. Model. 43 (2014) 114-123.

6. L. Becchetti, N. Solferino and M. E. Tessitore, Corporate social responsibility and profit volatility: Theory and empirical evidence, Ind. Corp. Change [In press].

7. L. Becchetti, V. Pelligra and S. F. Taurino, Other regarding preferences and reciprocity: Insights from experimental findings and satisfaction data. CEIS Working Paper No. 363. 
8. P. M. Bentler, EQS 6.1. Encino, CA: Multivariate software (2006).

9. M. M. Blair and L. A. Stout, A team production theory of corporate law, Va. Law Rev. 85(2) (1999) 247-331.

10. K. J. Blois, Trust in business to business relationships: An evaluation of its status, $J$. Manage. Stud. 36(2) (1999) 197-215.

11. K. A. Bollen, Structural Equation Models (Wiley Online Library, New York, 1998).

12. C. Borzaga and C. Carini, La cooperazione sociale: dinamica economica ed occupazionale tra il 2008 ed il 2013. [Online] Available at: http://www.euricse.eu/wp-content/uploads/ 2015/09/09-Carini-Borzaga.pdf (2014) last accessed 1 June 2014.

13. C. Borzaga, S. Depedri and E. C. Tortia, Organizational variety in market economies and the emergent role of socially oriented enterprises, in Social Enterprise and the Third Sector: Changing European Landscapes in a Comparative Perspective, eds. J. Defourny, L. Hulgård and V. Pestoff (Routledge, London, 2014). https://www.researchgate.net/ publication/295405980.

14. C. Borzaga and S. Sacchetti, Why social enterprises are asking to be multi-stakeholder and deliberative: An explanation around the costs of exclusion, Euricse Working Papers, 1575, Euricse (2015), https://papers.ssrn.com/sol3/papers.cfm?abstract_id=2594181.

15. C. Borzaga and E. C. Tortia, Worker motivations, job satisfaction, and loyalty in public and nonprofit social services, Nonprof. Volunt. Sec. Q. 35(2) (2006) 225-248.

16. L. Bruni, Reciprocità. Dinamiche di cooperazione, economia e società civile. Mondadori Eds.

17. M. Christen, I. Ganesh, D. Soberman, Job satisfaction, job performance, and effort: A reexamination using agency theory, J. Mark. 70(1) (2006) 137-150.

18. A. E. Clark and A. J. Oswald, Satisfaction and comparison income, J. Public Econ. 61(3) (1996) 359-381.

19. G. Degli Antoni, Intrinsic vs. Extrinsic motivations to volunteer and social capital formation, Kyklos 62(3) (2009) 359-370.

20. G. Degli Antoni and E. Portale, The effect of corporate social responsibility on social capital creation in social cooperatives, Nonprofit Volunt. Sect. Q. 40(3) (2011) 566-582.

21. P. F. Drucker, Managing the Non-Profit Organization: Principles and Practices (Harper Collins, New York, 1990).

22. Euricse (2015). Economia cooperativa. Rilevanza, evoluzione e nuove frontiere della cooperazione italiana. Euricse, European Research Institute on Cooperative and Social Enterprises, Trento. [Online] Accessed June 1 2017: http://www.euricse.eu/it/publications/economia-cooperativa-rilevanza-evoluzione-e-nuove-frontiere-della-cooperazioneitaliana/.

23. F. Fukuyama, Trust: The Social Virtues and the Creation of Prosperity (The Free Press, New York, 1995).

24. A. Giddens, The Constitution of Society: Outline of the Theory of Structuration (Polity Cambridge, 1984).

25. J. P. Gond, A. El-Akremi, J. Igalens and V. Swaen, Corporate social responsibility influence on employees. ICCSR Research Paper Series No. 54.

26. G. Grolleau, L. Tarik and M. Naoufel, Does ethical activism lead to firm relocation? Kyklos 57(3) (2004) 387-402.

27. J. K. Harter, L. S. Frank and L. M. K. Corey, Well-being in the workplace and its relationship to business outcomes: A review of the gallup studies, in eds. Flourishing: The Positive Person and the Good Life, L. M. K. Corey and J. Haidt (American Psychological Association, Washington D.C., 2003).

28. E. Kinnell, M. MacDougall and J. MacDougall, Marketing in the Not-for-Profit Sector (Oxford: Butterworth-Heinemann, 1997). 
29. S. Knack and P. Keefer, Does social capital have an economic payoff? A cross country investigation, Q. J. Econ. 112(4) (1997) 1251-1288.

30. T. D. Little, On the comparability of constructs in cross-cultural research: A critique of Cheung and Rensvold, J. Cross Cult. Psychol. 31(2) (2000) 213-219.

31. R. A. Litz, Two sides of a one side phenomenon: Conceptualizing the family business and business family as a möbius strip, Fam. Bus. Rev. 21(3) (2008) 217-236.

32. K. I. MacDonald, On the formulation of a structural model of the mobility table, Soc. Forces 60(2) (1981) 557-571.

33. A. McWilliams and D. Siegel, Corporate social responsibility and financial performance: Correlation or misspecification?, Strateg. Manage. J. 21(5) (2001) 603-609.

34. L. K. Muthén and B. O. Muthén, Mplus user's guide (Muthén \& Muthén, Los Angeles, CA 1998-2013).

35. K. K. Myers and K. Sadaghiani, Millennials in the workplace: A communication perspective on millennials' organizational relationships and performance, J. Bus. Psychol. 25(2) (2010) 225-238.

36. M. Osterloh, B. S. Frey and H. Zeitoun, Voluntary co-determination produces sustainable productive advantage, in Corporate Social Responsibility and Corporate Governance: The Contribution of Economic Theory and Related Disciplines, eds. L. Sacconi, M. Blair, R. E. Freeman and A. Vercelli (Palgrave Macmillan, Basingstoke, 2010), pp. 332-352.

37. R. D. Putnam, Making Democracy Work: Civic Traditions in Modern Italy (Princeton University Press, Princeton, 1993).

38. S. Rast and A. Tourani, Evaluation of employees' job satisfaction and role of gender difference: An empirical study at airline industry in Iran, Int. J. Bus. Soc. Sci. 3(7) (2012) 91-100.

39. R. Rob and P. Zemesky, Social capital, corporate culture and incentive intensity, Rand J. Econ. 33(2) (2002) 243-257.

40. F. Sabatini, Social capital and the quality of Economic development, Kyklos 61(3) (2008) 466-499.

41. F. Sabatini, F. Modena and E. C. Tortia, Do cooperative enterprises create social trust?, Small Bus. Econ. 42 (2014) 621-641.

42. L. Sacconi, Corporate social responsibility and corporate governance. Milan: Econometica Working Paper No. 38/2012. www.econometica.it, Accessed May 282017.

43. A. Sargeant, Marketing Management for Nonprofit Organizations (Oxford University Press, Oxford, 1999).

44. A. Semykina and S. J. Linz, Job satisfaction and perceived gender equality in advanced promotion opportunities: An empirical investigation, Kyklos 66(4) (2013) 591-619.

45. N. Solferino and V. Solferino, The corporate social responsibility is just a twist in a Mbius strip, Economics E-journal. http://www.economics-ejournal.org/economics/discussionpapers/2016-12 (2016).

46. E. C. Tortia, The impact of social enterprises on output, employment, and welfare, in The Economics of Social Responsibility: The World of Social Enterprises, eds. L. Becchetti and C. Borzaga (Routledge, London, 2010), pp. 55-72.

47. V. Valentinov, The meaning of nonprofit organization: Insights from classical institutionalism, J. Econ. Issues 45(4) (2011) 901-915.

48. S. A. Waddock and S. B. Graves, The corporate social performance-financial performance link, Strateg. Manage. J. 18(4) (1997) 303-319.

49. K. Yakubo, Y. Avishai and D. Cohen, Persistent currents in Möbius strips, Phys. Rev. B 67 (2003) 125319. 